\title{
Outra redução: a dinâmica interétnica na Limpia Concepción de Jeberos, nas missões jesuíticas do Marañon no século XVII ${ }^{1}$
}

Another reduction: the inter-ethnic dynamics in Limpia Concepción de Jeberos, in the $17^{\text {th }}$ century Marañon Jesuit Missions

Fernando Torres-Londoño*

\section{RESUMO}

$\mathrm{Na}$ trilha de apontar o protagonismo dos povos indígenas nos processos de conquista e colonização, o artigo propõe examinar o caso de uma missão jesuítica na Amazônia do século XVII pelos possíveis significados atribuídos a ela pelos Jebero, povo indígena que de fato a constituiu. Assim, a composição pluriétnica da missão é examinada pela dinâmica de relações definidas com base na condição de parente, inimigo ou estrangeiro.

Palavras-chave: indígenas; Missões; Mayna; Amazônia.
Abstract

In the path of pointing out the protagonism of indigenous peoples in the processes of conquest and colonization, this article proposes to examine the case of a Jesuit Mission in the $17^{\text {th }}$ century Amazon through the possible meanings assigned to it by the Jebero people who, in effect, built it. Thus, the multi-ethnic composition of the Mission is examined through the relationships dynamics based on one's role as relative, enemy or foreigner.

Keywords: Indians; Jesuit missions; Maynas; Amazon.

\section{As MISSÕES: REDUÇÃO MISSIONÁRIA DOS ÍNDIOS OU CONSTRUÇÃO} MÚLTIPLA DE UM NOVO ESPAÇO DE RELAÇÕES INTERÉTNICAS

A visão que se consagrou desde a conquista da América pelos espanhóis foi a de que estes teriam triunfado em razão de diversos tipos de superioridade, como também pelo fato de terem tido a habilidade de tirar vantagem das lutas e divisões internas dos estados e cacicados indígenas. Em paralelo à conquista,

\footnotetext{
* Departamento de História, Faculdade de Ciências Sociais, Pontifícia Universidade Católica de São Paulo. Rua Ministro Godói, 969, 4 andar, Perdizes. 05014-001 São Paulo - SP - Brasil. ltorresl@uol.com.br
} 
um grande esforço missionário teria conseguido cristianizar diversas populações indígenas que terminaram aderindo ao cristianismo. Já desde o final do XVI, havia consenso tanto no México como no Peru (ou outras áreas dos Andes) de que as missões deviam ser dirigidas àqueles grupos indígenas que não pertenciam às grandes unidades políticas, como os mexicas e os incas, nem aos expressivos cacicados existentes nas áreas das atuais Guatemala, Colômbia e Venezuela. Foi tal visão que levou as missões a se voltarem para as selvas tropicais ou para as áreas desérticas do norte do México e do sul do Peru. Para esses confins foram enviados os primeiros franciscanos e jesuítas, chegando posteriormente outras ordens religiosas.

As missões ou reduções jesuíticas tiveram um papel fundamental nesse processo de conversão, estando presentes em diversas partes do continente. Desde o século XVII, as reduções jesuíticas têm sido descritas com base na crônica missionária como pequenas cidades no sertão ou na selva, com igrejas bem terminadas, praça central e ruas paralelas com casas alinhadas onde viviam em perfeita ordem e harmonia, com as famílias indígenas dirigidas pelas suas próprias autoridades. Sob a direção de um ou dois padres os índios trabalhavam a terra comunitariamente, distribuindo seus ganhos entre a família, a missão e os mais necessitados, como as viúvas e os órfãos. Havia catequese todo dia, missas aos domingos e festas solenes em homenagem aos santos nos seus dias específicos. Aparentemente, além de uma ou outra bebedeira nada restaria da vida nômade, precária e de vadiagem que os jesuítas descreveram como o estilo de vida dos guaranis ou outros povos quando da sua chegada. Assim, graças à sua virtude e ao dedicado trabalho pedagógico, os jesuítas teriam transformado aquelas 'feras em homens'. É esta a visão que se recupera das crônicas religiosas e que chega até os nossos livros didáticos, a de que na redução ou missão jesuítica a civilização teria triunfado sobre a barbárie. ${ }^{2}$

Nos discursos dominantes do século XVII, e que continuaram vigentes no XVIII, XIX e XX, as reduções já se definiam como modelo do que deveria ser o caminho dos índios nômades, sem nenhuma forma de Estado na trajetória da barbárie à civilização: a saída da selva, a fixação em um lugar, o estabelecimento de uma aldeia com normas definidas pelos agentes brancos, a sujeição dos índios a esses agentes e a adoção de práticas de trabalho, educação, saúde e higiene europeus. 
Acreditamos que esse paradigma 'civilizatório' apresenta os jesuítas e brancos como agentes de um processo que contrapõe civilizados e selvagens, brancos e índios, processo no qual estes últimos eram entendidos como meros receptores passivos de uma civilização à qual não teriam nada a acrescentar. A pergunta que se coloca é a respeito do modo como os diversos povos indígenas que interagiram com os missionários entendiam as missões, até que ponto compartilhavam da visão dos brancos. Buscando esboçar uma resposta, o que propomos é uma inversão de olhares e de consideração de expectativas, deslocando a ênfase dos missionários para os índios. Realizando esse deslocamento, o que se quer é proporcionar elementos para entender as missões religiosas como lugares de redefinição das relações interétnicas sob a perspectiva dos índios, entendendo que eles também tiveram papel de protagonistas no processo, ou seja, tirando-os do silêncio e da invisibilidade em que têm sido colocados pelas chamadas 'fontes jesuíticas' como as cartas e a crônica missionária. ${ }^{3}$

Também se trata de trazer maior complexidade ao entendimento da conquista da América nas suas diversas faces, mostrando que as populações indígenas através de suas próprias dinâmicas relacionais interagiram como sujeitos perante as diversas presenças da colonização, abrindo um amplo leque de ações além de colaborações ou alianças. Tais atuações e modos de se relacionar levaram a reações, respostas, adaptações, concessões e negociações por parte dos poderes coloniais, muitas vezes mascaradas por discursos e retóricas que as apresentavam sob outros aspectos. ${ }^{4}$

Desse ponto de vista que desloca o foco da missão do missionário para os índios, acreditamos que as missões foram uma construção conjunta de índios e missionários, tendo para os índios significados diferentes daquele dos padres - praticamente o único até aqui considerado. Para os índios os significados da missão devem ter sido muito relacionados aos povos, às condições geográficas da região e às situações de cada momento de contato. Esses significados não devem ter coincidido com os dos padres, ao menos durante as primeiras duas gerações. Trabalhamos com a hipótese segundo a qual os índios 'saíram das selvas' ou 'desceram do sertão' - na formulação em português -, ou se assentaram junto aos padres, porque era isso que lhes convinha naquele momento, e cada povo ou grupo conferia seus próprios significados às relações que estabeleciam com os missionários. Os índios também teriam seu próprio 
entendimento do que seria permanecer ali e frequentar aquele lugar nomeado pelos padres como missão, com nomes como Santo Inácio, São Francisco etc.

\section{OS JEBERO E O ESTABELECIMENTO DA REDUÇÃO LIMPIA CONCEPCIÓN DE JEBEROS}

Para mostrar como se teria realizado essa 'construção conjunta da missão' serão apresentadas aqui as chamadas missões de Maynas ou do Marañon, nos afluentes do Amazonas, estabelecidas pelos padres jesuítas do colégio de Quito entre 1638 e $1767 . .^{5}$ Serão examinadas em particular as relações estabelecidas entre os missionários e os Jebero, um povo de língua Pano do rio Huallaga, afluente do Marañon no atual Peru. Segundo a documentação missionária, os Jebero foram a base para o estabelecimento da redução Limpia Concepción de Jeberos, que foi a cabeça ou centro das Missões de Maynas organizadas pelos jesuítas espanhóis na governação do mesmo nome e que existiram até a expulsão da Companhia de Jesus dos domínios espanhóis, em 1767.

A narrativa dos contatos e relações que os Jebero estabeleceram com os missionários pode ser recuperada em um 'informe' ou descrição redigida em 1661 pelo padre jesuíta Francisco de Figueroa, que nesse momento atuava como superior da missão de Maynas. ${ }^{6} \mathrm{O}$ texto deve ter merecido algumas cópias e circulado entre os jesuítas de Quito, já que é notória a cópia de parágrafos por outros escritores da Companhia de Jesus. ${ }^{7} \mathrm{O}$ informe sobre a missão teria sido solicitado pelo provincial e se destinaria não só aos historiadores da província como também aos superiores, para as tomadas de decisões. Particularmente no sentido de se posicionar em relação às objeções expostas nessa época por vários padres, tanto de Quito como de Lima, de que as missões amazônicas por se ocuparem de índios selvagens podiam resultar inúteis, conseguindo poucos frutos e expondo os padres ao perigo de serem assassinados pelos indígenas.

Consciente das dúvidas, resistências e objeções, o padre Figueroa organiza um informe destinado a defender as missões. Para dar força ao testemunho serve-se das cartas de missionários que havia encontrado no arquivo da missão, transcrevendo algumas na íntegra. Começa por contar as origens das missões com os padres Cugia e De la Cueva, e a seguir apresenta a situação de cada redução em termos de celebração dos sacramentos, ensino da doutrina 
e práticas cristãs, organização interna com autoridade indígena e meio de subsistência, tanto dos índios como dos missionários. Depois, faz um balanço das dificuldades encontradas, em particular a queda populacional ocasionada tanto por doenças como a varíola e o sarampo como pelas 'fugas' dos índios, apontando também aspectos positivos como o reconhecimento da autoridade dos padres pelos índios e o abandono das guerras entre as nações e da antropofagia. Finalmente enumera diversas medidas que permitiriam fortalecer a missão, como a imposição do quéchua, a abertura de caminhos para as comunicações, o estabelecimento de uma forja para produzir ferramentas e, é claro, o envio de mais padres para se ocuparem da missão de forma permanente.

O padre Figueroa se ocupa extensamente da Limpia Concepción de Jeberos. O padre tinha entrado em contato com os Jebero no início da sua atividade missionária, em 1642; entendia a língua, tinha sido seu missionário e participado com eles em diversas jornadas. Figueroa conta como os Jebero entraram em contato com padre De la Cueva, as principais ocorrências dos primeiros anos da missão e seu funcionamento na época. Nessa parte faz uma descrição detalhada do cotidiano da redução, de sua organização interna, do ensino da doutrina, da administração dos sacramentos, da igreja e da relação que os Jebero mantinham com seu padre missionário. $\mathrm{O}$ missionário justifica esse detalhamento dizendo que por ser 'exemplo' essa descrição, aí descreve todas as outras reduções e, assim, não precisa se repetir. Seu conhecimento dos Jebero se faz também presente quando se refere a eles ao tratar, de forma geral, de vários aspectos da vida e dos costumes, como suas crenças, o relacionamento com a morte e suas guerras.

Esse destaque a uma nação indígena foi comum entre os missionários cronistas e estaria relacionado com o convívio, com as boas relações estabelecidas e com a importância que lhes era atribuída para a manutenção do trabalho. Utilizamos aqui o texto do padre Figueroa sabendo bem os diversos filtros que nele interferem. O lugar, as circunstâncias da escrita, os destinatários e a retórica jesuítica do informe foram explicitados em artigo alguns anos atrás. ${ }^{8}$ Neste artigo o texto de Figueroa será utilizado naquilo que indique a perspectiva, os interesses e as expectativas dos Jebero em relação a outros grupos ou nações que eles consideravam parentes ou inimigos. ${ }^{9}$

A condição de parente está vinculada à relação de parentesco entendida a partir da consanguinidade ou da afinidade, seja ela próxima ou distante. ${ }^{10} \mathrm{O}$ 
inimigo se configura numa situação de antagonismo extremo, de hostilidade perene que coloca em risco a vida dos oponentes, pois o inimigo flecha e mata sua vítima, podendo até chegar a comê-la.

Mediante essas duas formulações grande parte dos povos da Amazônia e também de outras regiões se definem em relação a outros grupos ou nações. O entendimento dessas duas expressões e de suas contínuas reelaborações tem sido, pois, fundamental para o convívio dos índios entre si e deles com os brancos. Entre parentes e inimigos se configura uma terceira posição: o estrangeiro - alguém que não se conhece nem como parente nem como inimigo, mas que pode se tornar tanto um como outro. $\mathrm{Na}$ dinâmica das relações nas missões de Maynas essa terceira posição deve ter sido ocupada muitas vezes pelos missionários.

Também serão pontuadas no informe referências a situações ou aspectos que mostrem a relação que os Jebero foram desenvolvendo com os espanhóis (padres e soldados) e a forma como estes teriam se inserido na tensão contínua entre parentes e inimigos.

Tratando das origens das missões, Figueroa conta a chegada dos padres no momento em que os espanhóis combatem os índios Mayna na cidade de Borja, no rio Pastaza, quando estes teriam se insurgido contra a exploração sofrida pelos encomenderos. Nessa parte Figueroa segue as cartas do padre De la Cueva: este conta seus primeiros dias em Borja e menciona a chegada de uma manga de jeberos, os quais estariam ajudando os soldados espanhóis na captura e no castigo dos maynas rebelados. Os Jebero e os Mayna eram, pois, inimigos antes da chegada dos espanhóis, e a inimizade teria levado os primeiros a se aliarem aos espanhóis contra os segundos. A seguir De la Cueva menciona que os Jebero eram conhecidos como 'grandes matadores caribes', infundindo medo nos outros povos do Pastaza (Figueroa, 1986, p.178). Nessa carta e em outras transcritas por Figueroa, Lucas de la Cueva reitera, pois, essa condição dos Jebero de serem inimigos de muitos povos, introduzindo-os dessa forma na narrativa missionária. As missões de Maynas teriam se aproveitado da rede de relações preexistentes entre os grupos indígenas, dos quais herdaram não apenas os contatos com os grupos aliados, mas também as inimizades e as dinâmicas de relacionamentos.

No relato os Jebero estão junto aos espanhóis combatendo um inimigo comum. Mas Mariano de la Cueva diz que percebeu os caciques Jebero muito 
atribulados por verem como os espanhóis enforcavam os Mayna, cortavam narizes e esquartejavam seus corpos. Os caciques pensavam que, caso se indispusessem com os espanhóis, poderiam ter o mesmo destino. Chama atenção o fato de que os 'matadores' que 'cortavam cabeças e comiam fígados' tenham ficado perturbados por ver como os espanhóis tratavam seus inimigos. Segundo a descrição do missionário, os temidos Jebero teriam sentido medo ao ver os espanhóis 'administrar justiça'. Embora a crônica descreva procedimentos de punição que nenhum leitor europeu acharia estranho, o que de fato estava acontecendo em Maynas era o primeiro momento de contato em que duas sintaxes da guerra se confrontavam e se estranhavam. Segundo o relato do missionário, um inimigo maior estaria começando a se configurar para os Jebero. E tal situação é que teria permitido a aproximação entre De la Cueva e os caciques para 'os consolar', ganhando sua confiança.

De uma empatia mútua, surgida segundo o missionário pela percepção de sua bondade por parte dos índios, teria nascido um convite dos caciques para que fosse visitar os parentes no Huallaga e ficasse com eles. O padre teria aceitado essa oportunidade de converter aquela nação, apesar das muitas objeções do cabo da sua esquadra: tratava-se de índios conhecidos por serem matadores, nos quais não se podia confiar. Mas o missionário teria persuadido o cabo de esquadra e após algum tempo se armou uma expedição. Os Jebero conduziram aqueles estrangeiros (quase inimigos) por um labirinto de igarapés e florestas até seus parentes.

O que buscavam os Jebero ao se aproximarem do padre? Iriam se 'afeiçoar' a ele e o convidar para ir até seus parentes? Por que era importante para eles levar o padre e os soldados que eles ‘temiam' até seus parentes? Quais dinâmicas culturais os levariam a querer tratar com os 'cortadores de narizes'? A expectativa de um ganho de ferramentas em forma de presentes é uma explicação constante em todos os relatos de contato. O reconhecimento por parte dos Jebero de que os padres poderiam atuar como protetores ou mediadores perante inimigos visíveis e invisíveis aponta também para um fator importante em um universo de valorização das lideranças religiosas indígenas. Finalmente, o convite a estrangeiros armados e temidos, os quais bem poderiam ser inimigos numa dinâmica de inimizades, configurava uma iniciativa que colocava os Jebero na condução de um processo que poderia facilitar o mútuo entendimento. 
Segundo a carta de De la Cueva, a viagem pelos rios desconhecidos foi marcada pela fome, pelo incômodo e principalmente pelos temores dos espanhóis, tanto pelo fato de estarem entrando nos domínios de nações inimigas, como por temerem uma traição por parte dos Jebero, mas finalmente chegaram às aldeias localizadas nas cabeceiras do Huallaga. Lá, com presentes e manifestações de boa vontade, o padre fez acordos com os caciques: ele permaneceria com os índios caso estes se mudassem para a parte baixa do curso do rio, onde pretendia reunir vários povos e estabelecer uma redução. Houve resistência de caciques e de mohanes (lideranças religiosas indígenas), mas com promessas de mais ferramentas e da presença protetora do padre os primeiros grupos foram aceitando mudar-se caso encontrassem um lugar apropriado, e depois de uns meses foram chegando outros grupos. Os missionários concluíram: "sin duda que costó mucho tiempo y trabajo el reducirlos mucho de agasajo y dádivas, hachas, cuchillos, agujas, puyas, anzuelos, y otras osas que estiman" (Figueroa, 1986, p.179).

Como é próprio desses relatos que descrevem a fundação de reduções, o padre quase sempre fala na primeira pessoa e omite a atuação dos indígenas intérpretes, que por conhecerem a língua e a retórica argumentativa de sua nação, teriam de fato realizado a negociação que permitia a fundação. Fariam parte do grupo mediador e tradutor os caciques e indígenas que alguns meses antes já haviam saído das aldeias para atuar como aliados dos espanhóis na luta contra inimigos como os Mayna, e que no caminho tinham evitado cruzar com os Cocama, também seus inimigos. A carta do padre deixa claro que são esses caciques, que já haviam feito algum tipo de aliança com os espanhóis, os que têm a iniciativa tanto de ir procurar os parentes, como de convencê-los a se mudarem para perto do padre. Assim, a saída dos Jebero de suas aldeias, combinada entre os caciques que já haviam saído para guerrear e os que tinham ficado, é a continuidade de uma dinâmica de relações que existia desde antes da chegada do missionário e aponta para a mobilidade praticada pelos Jebero sob a tensão do confronto com o inimigo e a negociação da paz. Essa dinâmica seria tão forte que o grupo que havia saído e se aliado aos espanhóis conseguiu convencer os que ficaram, apesar de as lideranças religiosas indígenas arguirem que estavam indo embora para serem escravizados pelos espanhóis. 
Essa dinâmica estará presente também no processo de estabelecimento da redução acordado entre os caciques e os espanhóis. Na redução jesuítica os Jebero passarão a conviver com grupos de seus inimigos, os Mayna, os quais eles haviam derrotado e agora estavam sujeitos aos espanhóis, e também com os Paranapura, que aceitaram se estabelecer junto a eles. Ainda havia na redução outros dois inimigos - os Cutinana e os Achipure, e finalmente os Cocamilla, que não eram inimigos. Ou seja, inimigos antigos aceitaram ou foram obrigados a aceitar a proximidade, ajustaram-se a novas hierarquias e provavelmente subordinações. Assim, desde o início a redução se configura como um lugar pluriétnico permeado de tensões, o que explica o fato de cada nação fazer questão de viver separada em 'anexos', como mencionado na correspondência dos padres. Para os povos indígenas a redução era, pois, resultado de um delicado equilíbrio de relações interétnicas que poderia se romper a qualquer momento.

O contingente populacional da redução e a habilidade guerreira de seus componentes levam as autoridades coloniais de Borja e de outras governações a solicitarem a composição de uma expedição para a guerra contra os Jívaro. Tal expedição acabou sendo composta por soldados espanhóis, Jebero, Mayna e Paranapura. Assim os Jebero se integraram desde o início em uma dinâmica de guerra já conhecida, atuando novamente como inimigos - dos inimigos de seus aliados -, preservando desde a chegada à redução sua identidade de 'matadores' e se valorizando diante dos espanhóis e dos próprios inimigos, que os viam combatendo ao lado dos estrangeiros.

\section{A CRISE E A DEFINIÇÃO DE UM NOVO PATAMAR DE RELAÇÕES ENTRE OS JEBERO E OS MISSIONÁRIOS}

Segundo Figueroa, que transcreve cartas de De la Cueva transcorridos alguns anos e já quando a redução estava pronta para se configurar realmente como cristã, com a igreja sendo construída e os índios sendo batizados, o diabo semeou a discórdia que resultou em uma rebelião. Junto aos Mayna e Cocamilla, os Jebero se negaram a viver na redução, conspiraram contra o padre e partiram numa fuga em massa. O padre se salvou da morte, mas ficou sem índios remeiros nem canoas, apenas com um neófito e um rapaz de Moyobomba que o acompanharam durante um mês, até que finalmente chegou o 
padre Cugia com um tenente e reforços de soldados. Tanto De la Cueva como Figueroa responsabilizam os índios pela rebelião: estes teriam esquecido tudo o que o padre já havia feito para protegê-los dos espanhóis que os exploravam em Borja.

Uma leitura atenta do texto, que poderíamos chamar de indiciária, mostra que passados 4 anos do estabelecimento da redução, os Jebero estavam descontentes. As novas obrigações - ter de assistir à doutrina e às missas, por exemplo - os incomodavam, assim como o abandono de antigos costumes ter mais de uma mulher - e a renúncia às suas guerras e violências. Também consideravam excessivo todo o esforço dispensado na construção da igreja e repudiavam os regimes de obrigações e 'mitas' com que o missionário estava regulando seu trabalho, o que os impedia de se ausentarem da redução para visitar parentes, fazer guerras ou desenvolverem atividades regulares de pesca. Tudo isso levou os caciques a se indisporem com o padre, o qual insistiu na obediência à nova ordem e deu oportunidade para que uns Mayna entrassem em atrito com os Jebero, e estes terminaram por se configurarem como um inimigo maior: os espanhóis. As expectativas positivas de ter o padre por perto tinham acabado; o que se queria agora era distância (Figueroa, 1986, p.182).

Também ao contrário do que o missionário informava nas suas cartas, as crenças religiosas antigas se mantinham e era com base nelas que se entendiam com os espanhóis. Assim, na dramática carta que De la Cueva deixou na igreja, prevendo que podia ser morto durante a rebelião, carta que foi posteriormente transcrita por Figueroa, o padre insinua que algumas das pessoas que haviam saído da redução (os padres escrevem 'fugiram') teriam ido se ocultar dos espanhóis numa cidade localizada sob uma laguna, além do que o consumo da campana de zupay (planta alucinógena) os faria invisíveis. A carta associa essa crença ao índio Guamce, uma liderança religiosa que nas suas viagens, ao encontrar os espíritos (o diabo, na perspectiva do padre De la Cueva), se teria transformado primeiro em criança e depois em onça. A rejeição aos espanhóis se elaborava, pois, mediante atualizações de mitos e histórias sagradas (Figueroa, 1986, p.186).

Esta leitura dos relatos da rebelião nos mostra que os Jebero já assentados, vivenciando o que significava a redução para os padres e sem expectativas de que estes mudassem sua decisão de os controlar, resolveram abandonar a redução junto aos Mayna, Cocamilla e Paranapura, conferindo ao ato sentidos 
religiosos e políticos e estabelecendo um novo patamar de relação com os espanhóis.

Na crônica de Figueroa o desfecho da rebelião foi simples: depois das perseguições dos espanhóis e dos seus castigos exemplares - enforcamento e escravidão -, expostos à fome das selvas, os Jebero terminaram voltando à redução e se submetendo aos espanhóis e aos padres, permanecendo fiéis até a época em que se escrevia o informe. Nesse sentido, segundo Figueroa, teria sido muito útil a intercessão dos padres para salvar aqueles que se apresentavam: quase no momento da execução, estes acabaram sendo 'perdoados' pelo tenente que, explicitamente, atribuía tal perdão à bondade dos padres 'de que se perceberam reconhecidos'. O paradigma da missão-civilização que triunfa sobre a barbárie-selva organiza a narrativa e oculta os possíveis sentidos que os Jebero teriam dado a seu retorno, os quais se expressam a contrapelo da narrativa de Figueroa (1986, p.188).

Quais seriam esses sentidos? Teriam sido os Jebero tão ingênuos a ponto de não perceberem a manobra do tenente e do padre, o primeiro castigando e enforcando e o segundo concedendo o perdão, para ser reconhecido como salvador? As possibilidades de resposta estão nos textos a seguir, que transcrevemos de Figueroa:

Después de estos lances han quedado los jeberos tan asentados y se han doctrinado y domesticado tan bien, como digo arriba y son los más fieles para los padres y españoles, sirviéndoles con fidelidad en las armadas y descubrimientos que se hacen para pacificar nuevas naciones y reducirlas al santo evangelio y están por particular merced reservados de mita y tributo, dedicados solamente a las cosas de guerra y servicio de los padres en lo tocante a descubrimientos y reducciones. Entran en este privilegio los Cocamas de Huallaga y los Paranapuras. Con que no sólo se ha les ha seguido provecho para sus almas y su salvación, sino para las de otras naciones a que ayudan y concurren con fidelidad y sujeción. Y son como frontera que tiene la ciudad para su resguardo y de los Padres, para que otras gentes no se atrevan a intentar alzamientos y barbaridades por ven que tienen los españoles gente fiel de quien valerse cuando lo intenten. (Figueroa, 1986, p.188)

No relato de Figueroa a volta à missão resultou da derrota dos Jebero. Há um novo começo para a redução, fundamentado na adoção da doutrina e da 'domesticação' dos Jebero, o que supõe a incorporação definitiva na missão e o 
abandono das práticas anteriores, das quais há vários exemplos em outras partes do texto. Esse novo começo se expressa na fidelidade dos Jebero para com os espanhóis e os padres. Porém, o texto de Figueroa é claro e revelador no que se refere à dinâmica de relações interétnicas que estava na base da 'restauração da redução': os Jebero, Cocamas e Paranapuras rebeldes voltam 'perdoados' para defender a missão dos inimigos dos espanhóis. Isto constitui uma nova realidade, definida por reconhecimentos e 'acordos' dos dois lados.

Como em outros momentos, Figueroa silencia a respeito dos caciques e intérpretes que teriam participado no acerto das relações que passaram a definir o novo funcionamento da redução da Limpia Concepción de Jeberos. Assim, para a análise textual só temos o registro de Figueroa, no qual os Jebero, junto aos Cocamilla e os Paranapuras, voltam como reais aliados que impõem condições. Essas condições passavam por não serem submetidos a obrigações de tributos e de trabalho impostas pelos espanhóis sobre os índios, chamadas de 'mitas'. Os Jebero retornam para se dedicarem às 'coisas da guerra'. Eles voltam à redução para serem a 'armada de missão', como já escrevemos anos atrás. ${ }^{11} \mathrm{Ou}$ seja, eles voltavam para seguir sendo Jebero, inimigos temidos por todos. Mais ainda, foi a eles que corresponderam os 'descubrimientos y reducciones', quer dizer, o crescimento da missão passou a depender das entradas e expedições dos Jebero.

Porém, são outros interesses, diferentes daqueles dos missionários, os que guiam essa expansão. Tendo endossado sua condição de inimigos de muitos e aberto a possibilidade de convívios não violentos no interior da missão, os Jebero se colocam no topo da hierarquia da composição multiétnica da redução, definindo quem é parente, estrangeiro ou inimigo. Assim, não é a simples aliança ou o aproveitamento de oportunidades (como pensávamos em 2007) que teria levado os Jebero de volta à missão, mas a afirmação de sua identidade e a redefinição a seu favor das relações interétnicas. Voltando para a redução, porém na condição de ser 'seu resguardo', os Jebero tiveram reconhecido seu ethos guerreiro e asseguraram o respeito dos estrangeiros com os quais se aliaram, passando a ver reconhecida a sua forma de ser independente, como também sua identidade construída sob violência. 
A LIMPIA CONCEPCIÓN DE JEBEROS:

ENTRE PARENTES, AUCAS E ESTRANGEIROS

Figueroa se refere à Limpia Concepción de Jeberos nestes termos:

hoy lo es de doctrina cristiana y sirve de ejemplar y ayuda para que otros se reduzcan y hagan cristianos, y habiendo vivido tan a su voluntad y fieras costumbres, al presente están con suma sujeción, que aun para sus paseos en tiempo de tortugas y frutas, pescas y otras cosas necesarias a su sustento, piden licencia al padre, quien les señala los días que han de tardar, porque no falten mucho de sus casas. También la piden para sus bebidas, que son de ordinario los domingos y no pasan de la hora en que les tocan las Ave-Marías. (Figueroa, 1986, p.190)

A 'suma sujeição' da presença dos Jebero na redução tem aqui duas contrapartidas surgidas, evidentemente, no âmbito dos acordos que sustentam a Limpia Concepción de Jeberos. A primeira é a garantia da mobilidade, que reconhece a liberdade de ir e vir para as atividades econômicas e de sobrevivência. Pelo entendimento entre os missionários e os Jebero, as antigas ausências para responder aos ciclos de pesca no verão (vitais para o equilíbrio alimentar da missão) deixam de ser desobediências e fugas como na crise que conduziu à rebelião e passam a ser acordos, que no âmbito público da redução se expressam nos protocolos de 'pedir' licença ao padre e de fixar os dias que passam fora da missão.

A segunda é a permanência da festa indígena, a ser realizada aos domingos, o mesmo dia da missa, mas na parte da tarde. Como aparece em diversos textos, ela mantém seus elementos estruturantes: o consumo de bebida com as desinibições e comportamentos que ela suscita e que vão do ridículo à violência das brigas; a música e os cantos para chamar os espíritos protetores ou evocar as guerras; as danças que umas vezes unem e outras separam os indivíduos, expressando a unidade e a diferença; finalmente, sua função de atualização da memória dos grupos. Mantidas assim através da integração no calendário da missão, as festas indígenas são fundamentais na dinâmica de relações interétnicas e de convivência entre parentes, estrangeiros e inimigos e passam a caracterizar a vida na Limpia Concepción de Jeberos.

Constituindo a redução mediante esses acordos, os Jebero se dedicaram ao que era sua função fundamental nos primeiros anos, e é disso que Figueroa 
dá conta: descobrimento e pacificação de novas nações para reduzi-las ao evangelho. Fizeram isso dando continuidade à sua dinâmica de procurar parentes e combater inimigos. A respeito do primeiro aspecto, diz Figueroa dos Jebero:

Mediante estos indios se ha procurado solicitar otras naciones a que acuden con fidelidad. Así lo hicieron con los cutinanas que es uno de sus anexos. Trataron de irles a hablar, dándose por parientes de ellos, en orden a traerlos a esta reducción de jeberos, con licencia que tenían de la justicia y del padre, porque conviene que semejantes acciones no las hagan sin esas licencias y registros.

Servindo-se de "intérpretes, uno o dos que tenían de la misma nación, hallándolos en sus tierras, les propusieron lo que pretendían en orden a la amistad, convidándoles a que se vinieran a vivir a jeberos" (Figueroa, 1986, p.192).

A aproximação com os Cutinana, pelo que diz Figueroa, foi uma decisão dos Jebero, que fizeram-na por se tratar de parentes. Na dinâmica do novo arranjo que se estava formando, importava que os que eram reconhecidos como parentes ficassem mais próximos e não se tornassem inimigos da redução. Ao decidirem atrair os Cutinana para a redução, devem ter influenciado diversas formas de proximidades e situações internas. Os caciques Jebero devem ter informado os espanhóis, dos quais devem ter obtido ferramentas e outros presentes absolutamente necessários para conseguirem a aproximação e a concordância em vir para a redução. Papel importante devem ter cumprido os dois intérpretes por pertencerem de alguma forma aos dois universos de parentes. Fizeram tudo isso sem os espanhóis, mas fazendo-os presentes nas 'dádivas' e ferramentas. Ou seja, utilizando a forma de aproximação própria da missão, que combinava o novo e a dinâmica tradicional de relações de cada grupo. Utilizando o valor das ferramentas europeias mas ao estilo indígena, com festas protocolares que celebravam a alegria do encontro com os parentes. $\mathrm{O}$ resultado de tudo isso deveria ser a incorporação dos parentes à redução, em um 'anexo'. Figueroa diz que a aproximação foi bem sucedida, mas que as fomes e as epidemias diminuíram o anexo dos Cutinana (Figueroa, 1986, p.193).

Se na aproximação com parentes os Jebero foram decisivos e ela se deu rápido, o contato com o inimigo nos marcos da redução exigiu dos indígenas uma mudança de seu entendimento na relação com o inimigo, mudança que 
foi lenta. Os Jebero, como muitos povos amazônicos de ethos guerreiro, entendiam que perante o inimigo não eram muitas as opções: o ataque mortal, a proteção da distância e da desconfiança e a permanência imperativa da vingança. Já para os jesuítas todas as nações, por 'bárbaras' que fossem, deveriam ser trazidas para a fé católica, quer pelo convencimento, quer pela força. Nas missões do Marañon, as nações ou povos que resistiam e reagiam com violência, representando perigo para as reduções, eram nomeadas com a palavra quéchua auca que, na tradução em espanhol, é inimigo. Assim, os que ficavam fora da missão, negando-se a reduzir e aldear e ameaçando a redução, eram aucas. Mas, se com diversas estratégias ou situações esses aucas eram reduzidos e introduzidos na redução, eles poderiam tornar-se, para os missionários, 'índios amigos' (formulação comum nas crônicas) e parte da missão. Para os Jebero e outros povos guerreiros que depois vieram para as missões como os Cocama, isso significou mudar o entendimento de que o destino do inimigo era a morte, passando a ser a sujeição, captura, controle e assimilação na proximidade e na vida coletiva da missão.

Substituir a morte pela sujeição implicou também a invenção de uma estratégia perante o inimigo, a qual admitia vários estágios e momentos, cada um com fins próprios. Assim se podia fazer guerra (aplicada como castigo pelos espanhóis e praticada como vingança pelos índios); recorrer à intimidação pelo medo dos matadores indígenas que devoravam seus inimigos e ao terror dos espanhóis que enforcavam e cortavam narizes; organizar assaltos-surpresa às aldeias inimigas (normalmente à noite, seguindo as táticas de guerrilha indígena) destinados a capturar crianças e adolescentes que, cristianizados, se tornariam intérpretes e mediadores num futuro próximo, em 'aproximações de boa vontade'; e realizar esses contatos pacíficos alimentados a ferramentas e presentes em momentos de fragilidade numérica ou anímica do inimigo, depois de sucessivas derrotas ou epidemias.

\section{Concluindo}

Os Jebero participaram em todos esses momentos de 'descobrimentos' e ampliações da missão, dentro de coletivos interétnicos maiores, ocupando posições decisivas como guias, 'guerreiros de assalto' e comandos de contato, dando vazão a seu ethos guerreiro e mantendo sua identidade de 'antigos 
matadores'. Sua participação deve ter sido menor quando se faziam necessárias negociações e acordos, ficando estes a cargo de parentes dos inimigos que já viviam na missão, os quais, por sua vez, os Jebero tinham ajudado a capturar em expedições e operações anteriores.

Incorporando os aucas à missão (onde já conviviam parentes próximos e distantes, antigos e recém-chegados), os Jebero devem ter comandado um seguro e lento processo de inclusão de estrangeiros mediante o estabelecimento 'próximo' de reduções e anexos em condições de relações assimétricas e de diversos graus de inferioridade. Lentamente os antigos aucas, agora subordinados às etnias principais das missões, deixavam de ser inimigos para se tornarem 'índios amigos' e, finalmente, com casamentos interétnicos, podiam chegar a ser parentes. Isso se realizou mediante múltiplos processos de assimilação tanto de origem indígena como jesuítica, ou elaborados na própria dinâmica interétnica da redução pautada pelos Jebero.

\section{NOTAS}

${ }^{1}$ A pesquisa que originou este texto faz parte do Projeto de Produtividade em Pesquisa/ CNPq "Jesuitas y pueblos indígenas en la Amazonia española y portuguesa (1680-1750): representaciones y conflictos". Essa pesquisa se realiza dentro do grupo Povos Indígenas e História nas Américas, na PUCSP.

${ }^{2}$ Essa visão pode ser encontrada em obras de autores de referência no estudo das missões jesuíticas, como a de REY F., Jose del S. J. (Org.). Misiones jesuíticas en la orinoquia. San Cristobal: Universidad Católica del Tachira, 1992.

${ }^{3}$ De forma pioneira essa outra perspectiva da missão jesuítica foi proposta por MELIA, Bartolomeu. El Guaraní conquistado y reducido: ensayos de Etnohistoria. 4.ed. Asunción: Centro de Estudios Antropológicos Universidad Católica, 1997. p.178.

${ }^{4}$ Para esse tipo de abordagem das missões ver WILDE, Guillermo. Religión y poder em las missiones de guaranis. Buenos Aires: Ed. SB, 2009.

${ }^{5}$ Para uma visão geral das missões de Maynas, ver: NEGRO, Sandra. Maynas, una misión entre la ilusión y el desencanto. In: MARZAL, Manuel; NEGRO, Sandra. Un reino en la frontera. Lima/Quito: PUCP, Ed. Abya-Yala, 1999. p.270. Para uma abordagem etnológica do início da missão de Maynas ver TAYLOR, Anne Christine. História Pós-colombiana da Alta Amazônia. In: Manuela CARNEIRO DA CUNHA, Manuela (Org.). História dos índios no Brasil. São Paulo: Companhia das Letras, 1992. p.218-219.

${ }^{6}$ FIGUEROA, Francisco. Informe de las misiones de el Marañon, Gran Pará o río de las 
Amazonas. Monumenta Amazónica. Informes de jesuítas en el Amazonas, 1660-1684. Iquitos: Ceta, 1986.

${ }^{7}$ É o que acontece com a obra de MARONI, Pablo. Noticias auténticas del famoso río Marañón. Monumenta Amazónica B. Iquitos: Ceta, 1988.

${ }^{8}$ LONDOÑO, Fernando Torres. La búsqueda de la mayor gloria de Dios, en la dinámica argumentativa misionera jesuítica: el Informe de las Misiones del Marañón del padre Francisco de Figueroa de 1661. Revista Theológica Xaveriana, n.162, 2007.

${ }^{9}$ Sobre a compreensão, elaboração e relacionamento da condição de inimigo entre as sociedades indígenas, tem sido muito instigante para nossa pesquisa VILAÇA, Aparecida. Quem somos nós? Os 'Wari' encontram os brancos. Rio de Janeiro: Ed. UFRJ, 2006. p.142ss. Ver também: VIVEIROS DE CASTRO, Eduardo. Imanência do inimigo. In: . A inconstância da alma selvagem e outros ensaios de antropologia. São Paulo: Cosac Naify, 2002. p.270.

${ }^{10}$ Sobre parentes, aliados e afins entre grupos amazônicos ver a discussão levantada por CABALZAR, Aloisio. Filhos da cobre da pedra: organização social e trajetória tukuya no rio Tiquié (noroeste amazônico). São Paulo: Ed. Unesp; Isa; Rio de Janeiro: Nuti, 2009. p.104ss.

${ }^{11}$ LONDOÑO, Fernando Torres. Contato, guerra e negociação: redução e cristianização de Maynas e Jeberos pelos jesuítas na Amazônia do século XVII. História Unisinos, São Leopoldo (RS), v.4, 2007.

Artigo recebido em 20 de junho de 2012. Aprovado em 1ํ de setembro de 2012. 